\title{
Association between socioeconomic status and oral health behaviors: The 2008-2010 Korea national health and nutrition examination survey
}

\author{
JUN-BEOM PARK $^{1}$, KYUNGDO HAN $^{2}$, YONG-GYU PARK ${ }^{2}$ and YOUNGKYUNG KO ${ }^{1}$ \\ Departments of ${ }^{1}$ Periodontics and ${ }^{2}$ Biostatistics, College of Medicine, \\ The Catholic University of Korea, Seoul 06591, Republic of Korea
}

Received March 10, 2015; Accepted April 6, 2016

DOI: $10.3892 / \mathrm{etm} .2016 .3679$

\begin{abstract}
Socioeconomic status (SES) has been reported to be associated with oral health behavior. Therefore, the present study was conducted to assess the relationship between SES and oral health behaviors in a large sample of the Korean population. Data from the Korea National Health and Nutrition Examination Survey, which was conducted between 2008 and 2010 by the Division of Chronic Disease Surveillance under the Korea Centers for Disease Control and Prevention and the Korean Ministry of Health and Welfare, were used in the present study. Daily tooth brushing frequency and the use of secondary oral products according to demographic variables and anthropometric characteristics of the participants were assessed. Multivariate logistic regression analyses were used to analyze the associations between daily tooth brushing frequency and the use of secondary oral products, and SES, urban/rural residence, body mass index (BMI), alcohol intake and smoking. An association between SES and tooth brushing frequency and the use of secondary oral products was detected after adjustment. Following adjustment for age, gender, BMI, smoking, drinking, exercise, energy intake, fat intake, periodontal treatment needs and education or income, the adjusted odds ratios and $95 \%$ confidence intervals $(\mathrm{CI})$ of tooth brushing $\geq 3$ per day in the highest income group were 1.264 (95\% CI, 1.094-1.460) and 2.686 (95\% CI, 2.286-3.155) for highest education level group. The adjusted odds ratios for the use of secondary oral products in the highest income and highest education groups were 1.835 (95\% CI, 1.559-2.161) and 5.736 (95\% CI, 4.734-6.951), respectively, after adjustment for age, gender, smoking, BMI, exercise, calorie intake, periodontal treatment requirements or income. The present study demonstrated an association between SES and oral health behaviors in a large sample of the Korean
\end{abstract}

Correspondence to: $\mathrm{Dr}$ Youngkyung Ko, Department of Periodontics, College of Medicine, The Catholic University of Korea, 222 Banpo-Daero, Seocho-Gu, Seoul 06591, Republic of Korea E-mail:ko_y@catholic.ac.kr

Key words: epidemiology, oral hygiene, oral health, social class population. Within the limits of the present study, income and education were suggested as potential risk indicators for oral health behaviors; therefore, patients with a low SES should be investigated further, in relation to oral health.

\section{Introduction}

Good oral hygiene behavior is necessary for the maintenance of oral health. Periodontal diseases and tooth decay may be exacerbated without good oral hygiene. Oral health is also significantly associated with various systemic diseases such as cardiovascular disease, diabetes mellitus, chronic respiratory disease and rheumatoid arthritis (1-2). Previous studies have examined the impact of socioeconomic status (SES) on the health-related behaviors of adults (3-5). It has been demonstrated that the effects of social inequalities on oral health are observable regardless of the method of social classification and the measure of oral health or disease (6). A previous study conducted among adults has indicated that individuals from lower socioeconomic positions tend to have a higher degree of clustering of multiple risk factors for poor dental hygiene, as compared with those in higher socioeconomic positions (3). Individuals belonging to higher income groups are less likely to report dental pain and more likely to be satisfied with their oral health status than their lower socioeconomic counterparts (5). It was also observed that socioeconomic factors are considered to be a strong risk factor for school children caries (7). One study on the trends in tooth loss in Swedish women observed that women in lower social groups tended to have less remaining teeth, irrespective of age (8). Previous studies have investigated the association between risk of mortality and oral care habits. Paganini-Hill et al (9) followed 5,611 men and women for 17 years in the United States and reported that people with poor oral hygiene habits had a higher risk of mortality (9). A study on 21,730 community residents in Japan also reported that people with poor oral health care habits had a higher risk of mortality (10).

In a previous study, individuals in the lower socioeconomic groups of the Korean Population were significantly more likely to require periodontal treatment (11). However, information regarding the association between SES and oral health behaviors in the Korean population remains limited. 
The present study was performed to assess the association between SES and oral health behaviors in a large sample of the Korean population using data from Korea National Health and Nutrition Examination Survey (KNHANES).

\section{Materials and methods}

Data collection. Data from the KNHANES, which was conducted between 2008 and 2010 by the Division of Chronic Disease Surveillance under the Korea Centers for Disease Control and Prevention and the Korean Ministry of Health and Welfare, were used for the present study (12). KNHANES is a nationwide study of non-institutionalized civilians that uses a stratified and multi-stage probability sampling design with a rolling survey-sampling model. Sampling units were based on the population and housing consensus from the 2005 National Census Registry in Korea, which includes age, gender and geographic area (13). In total, 20,730 individuals aged $\geq 19$ years were targeted for the survey, and 19,219 participants with complete data, including SES, were used in the present study.

Demographic and lifestyle variables. All participants were asked about their lifestyle and socioeconomic characteristics by trained interviewers. Age, alcohol consumption, smoking status, residential area, daily energy intake, fat intake and marital status were considered possible confounding factors in the present study.

Participants were divided into three groups according to the amount of alcohol consumption reported per day: Non-drinker, light to moderate drinker (1-30 g/day) and heavy drinker (>30 g/day) (14). Smoking status was categorized into three groups in accordance with respondents' answers on the self-report questionnaire: (i) Non-smokers, those who had never smoked or had smoked $<100$ cigarettes in their life; (ii) ex-smokers, those who had smoked in the past but had stopped smoking; and (iii) current smokers, those who were smoking currently and had smoked $\geq 100$ cigarettes in their life (15). Individuals were regarded as regular physical exercisers if they performed moderate exercise at least 5 times per week for at least 30 min per session, or performed vigorous exercise at least 3 times per week for at least $20 \mathrm{~min}$ per session (16).

A face-to-face interview was conducted to obtain data about place of residence (rural vs. urban) and occupation of the participants (17). Residential areas were categorized into urban areas (administrative divisions of 'dong') and rural areas (administrative divisions of 'eup' or 'myeon') (14). Daily food intake was assessed using the 24-h recall method, and a food frequency questionnaire was used to determine food consumed the previous day. Energy and fat intake were calculated using a food database developed for the KNHANES and the food composition table published by the National Rural Living Science Institute under the Rural Development Administration (18).

Socioeconomic variables. In the present study, SES was assessed by monthly household income and education level. Monthly household income levels were divided into quartiles. The first quartile included households with a monthly income
$<1092.4$ USD, the second quartile included those with an income of 1092.4-2334.3 USD, the third included those with an income of 2334.3-3734.8 USD and the fourth included those with an income $>3734.8$ USD. Education levels were categorized into four groups according to the number of years of schooling completed: (i) < 7 years (elementary school graduate or lower); (ii) 7-9 years (middle school graduate or some middle school); (iii) 10-12 years (high school graduate or some high school); and (iv) $>13$ years (university or higher) (14).

Anthropometric measurements. Body weight and height were measured to the nearest $0.1 \mathrm{~kg}$ and $0.1 \mathrm{~cm}$, respectively, whilst participants were wearing light indoor clothing without shoes (19). Body mass index (BMI) was calculated using the following formula: BMI=body weight $(\mathrm{kg}) /$ height $^{2}$ $\left(\mathrm{m}^{2}\right)$. Waist circumference was measured at the narrowest point between the lower border of the rib cage and the iliac crest.

Oral health behaviors and periodontal treatment. In the present study, the time of day when tooth brushing was performed and the use of secondary oral products were assessed. Times of day included: Before or after breakfast, lunch, dinner and before sleeping. The frequency of daily tooth brushing was conducted according to the total number of tooth brushing incidences per day. Secondary oral products included dental floss, mouthwash, interdental brushes and electric toothbrushes (15).

The World Health Organization community periodontal index (CPI) was used to assess periodontal treatment needs and periodontal disease was defined as CPI $\geq 3$ (20). A CPI score of 3 indicated that $\geq 1$ site had a $>3.5 \mathrm{~mm}$ pocket in the index teeth, which are $11,16,17,26,27,31,36,37,46$ and 47 according to the Federation Dentaire Internationale system (21). The mouth was divided into sextants. A CPI probe (PWHO; Osung MND Co., Ltd., Seoul, Korea) with a $0.5 \mathrm{~mm}$ ball tip was used. A sextant was examined only if there were $\geq 2$ teeth present that were not scheduled for extraction. If no index teeth were present in a sextant qualifying for examination, all remaining teeth were examined and the highest score was recorded as the score for that sextant. A probing force of $20 \mathrm{~g}$ was used. Trained and calibrated dentists examined the periodontal status of the participants, and the mean inter-examiner Kappa value was 089 [95\% confidence interval (CI), 0.55-1.00] (15,22-23).

Chewing and speech ability, attendance at a dental checkup within a year and incidence of caries in permanent teeth were evaluated.

Statistical analyses. Data were presented as either mean \pm standard error or as percentage (standard error), as indicated. Statistical analyses were performed using the survey procedure of the SAS 9.2 statistical software package for Windows (SAS Institute, Inc., Cary, NC, USA) to account for the complex sampling design. Two-sided $\mathrm{P}<0.05$ were considered to indicate a statistically significant difference. Analysis of variance was applied to examine the relationship between the daily frequency of tooth brushing, use of secondary oral products per day, and SES. 
Table I. Characteristics of the study population.

Daily tooth brushing frequency

\begin{tabular}{|c|c|c|c|c|c|c|c|c|}
\hline \multirow[b]{2}{*}{ Variable } & & \multirow[b]{2}{*}{ P-value } & & \multirow[b]{2}{*}{ P-value } \\
\hline & $0-1$ & 2 & $\geq 3$ & & 0 & 1 & $\geq 2$ & \\
\hline Age, years & $49.8 \pm 0.6$ & $46.1 \pm 0.3$ & $42.1 \pm 0.2$ & $<.0001$ & $45.3 \pm 0.3$ & $41.2 \pm 0.3$ & $39.6 \pm 0.4$ & $<.0001$ \\
\hline Male, $\%$ & $65.7(1.3)$ & $52.3(0.7)$ & $46.3(0.5)$ & $<.0001$ & $52.4(0.4)$ & $45.7(0.8)$ & $37.0(1.5)$ & $<.0001$ \\
\hline Body mass index, $\mathrm{kg} / \mathrm{m}^{2}$ & $24.2 \pm 0.1$ & $23.9 \pm 0.1$ & $23.4 \pm 0.0$ & $<.0001$ & $23.7 \pm 0.0$ & $23.4 \pm 0.1$ & $23.2 \pm 0.1$ & $<.0001$ \\
\hline Waist circumference, $\mathrm{cm}$ & $83.7 \pm 0.3$ & $82.3 \pm 0.2$ & $80.0 \pm 0.3$ & $<.0001$ & $81.7 \pm 0.2$ & $79.7 \pm 0.2$ & $78.7 \pm 0.3$ & $<.0001$ \\
\hline Energy intake, kcal/day & $1958.9 \pm 32.5$ & $1963.1 \pm 16.7$ & $2020.2 \pm 12.6$ & 0.0098 & $1989 \pm 12.1$ & $2012 \pm 17.8$ & $2041.1 \pm 32.3$ & $<.0001$ \\
\hline Fat intake, g/day & $15.7 \pm 0.3$ & $17.2 \pm 0.2$ & $18.7 \pm 0.1$ & $<.0001$ & $17.5 \pm 0.1$ & $19.2 \pm 0.2$ & $19.9 \pm 0.3$ & $<.0001$ \\
\hline Rural residence, $\%$ & $27.3(2.4)$ & $20.7(1.8)$ & $16.6(1.7)$ & $<.0001$ & $21.1(1.7)$ & $13.8(1.4)$ & $11.1(1.6)$ & $<.0001$ \\
\hline Married, \% & $66.7(1.5)$ & $70.8(0.8)$ & $68.3(0.8)$ & 0.0102 & $66.9(0.7)$ & $73.3(1.0)$ & $74.5(1.7)$ & $<.0001$ \\
\hline Exercise, \% & $23.3(1.3)$ & $25.5(0.7)$ & $25.3(0.6)$ & 0.2833 & $24.4(0.5)$ & $27.1(0.8)$ & $26.5(1.5)$ & 0.0073 \\
\hline PTN, \% & $39(1.6)$ & $34.6(1.0)$ & $24.5(0.7)$ & $<.0001$ & $31.0(0.8)$ & $24.7(0.8)$ & $20.5(1.4)$ & $<.0001$ \\
\hline Checkup within year, \% & $22.7(1.4)$ & $24.4(0.8)$ & $28.6(0.8)$ & $<.0001$ & $22.8(0.7)$ & $34.2(1.0)$ & $42.0(1.6)$ & $<.0001$ \\
\hline Caries in $\mathrm{PT}, \%$ & $89.7(0.9)$ & $89.4(0.5)$ & $90.7(0.4)$ & 0.0658 & $89.3(0.4)$ & $92.0(0.5)$ & $93.3(0.9)$ & $<.0001$ \\
\hline Smoking, \% & & & & $<.0001$ & & & & $<.0001$ \\
\hline Non-smoker & $43(1.4)$ & $52.4(0.7)$ & $59.4(0.5)$ & & $54.0(0.4)$ & $59.1(0.8)$ & $64.0(1.5)$ & \\
\hline Ex-smoker & $21.2(1.1)$ & $17.1(0.5)$ & $16.4(0.4)$ & & $17.3(0.4)$ & $16.6(0.6)$ & $15.0(1.2)$ & \\
\hline Current smoker & $35.8(1.4)$ & $30.4(0.7)$ & $24.2(0.5)$ & & $28.7(0.5)$ & $24.2(0.8)$ & $21.0(1.5)$ & \\
\hline Alcohol intake, $\%$ & & & & $<.0001$ & & & & $<.0001$ \\
\hline None & $26.3(1.3)$ & $24.4(0.7)$ & $21.3(0.5)$ & & $23.8(0.5)$ & $20.0(0.7)$ & $19.8(1.3)$ & \\
\hline Light-moderate & $47.9(1.4)$ & $54.7(0.8)$ & $61.2(0.6)$ & & $56.0(0.5)$ & $62.4(0.9)$ & $64.5(1.6)$ & \\
\hline Heavy & $25.9(1.3)$ & $20.9(0.6)$ & $17.5(0.5)$ & & $20.2(0.4)$ & $17.5(0.7)$ & $15.6(1.3)$ & \\
\hline Chewing, $\%$ & & & & $<.0001$ & & & & $<.0001$ \\
\hline Great discomfort & $12.5(0.9)$ & $7.7(0.4)$ & $3.8(0.2)$ & & $6.7(0.3)$ & $3.7(0.3)$ & $2.4(0.5)$ & \\
\hline Discomfort & $24.4(1.2)$ & $21.9(0.7)$ & $20.2(0.5)$ & & $22.0(0.5)$ & $19.6(0.7)$ & $16.5(1.1)$ & \\
\hline Minor problems & $16.6(1.1)$ & $16.6(0.6)$ & $14.4(0.6)$ & & $14.6(0.5)$ & $16.2(0.6)$ & $19.1(1.3)$ & \\
\hline Minimal problems & $18.9(1.1)$ & $22.9(0.7)$ & $27.7(1.0)$ & & $24.5(0.8)$ & $27.1(0.9)$ & $30.1(1.6)$ & \\
\hline No discomfort & $27.6(1.4)$ & $30.9(0.9)$ & $33.8(1.0)$ & & $32.1(0.9)$ & $33.4(1.0)$ & $31.9(1.7)$ & \\
\hline Speech, $\%$ & & & & $<.0001$ & & & & $<.0001$ \\
\hline Great discomfort & $4.3(0.5)$ & $1.6(0.2)$ & $0.8(0.1)$ & & $1.6(0.1)$ & $0.8(0.1)$ & $0.5(0.2)$ & \\
\hline Discomfort & $10.9(0.9)$ & $6.9(0.4)$ & $5.5(0.3)$ & & $7(0.3)$ & $5.3(0.4)$ & $3.6(0.6)$ & \\
\hline Minor problems & $12.1(1.0)$ & $8.8(0.5)$ & $6.3(0.3)$ & & $7.4(0.3)$ & $7.9(0.5)$ & $7.8(0.9)$ & \\
\hline Minimal problems & $20.3(1.1)$ & $22.7(0.8)$ & $27.3(1.2)$ & & $25.8(0.9)$ & $24.3(0.9)$ & $23.9(1.6)$ & \\
\hline No discomfort & $52.4(1.5)$ & $60.0(0.9)$ & $60(1.2)$ & & $58.2(1)$ & $61.7(1.1)$ & $64.1(1.8)$ & \\
\hline
\end{tabular}

Data are represented as the mean \pm standard error of the mean or as percentages (standard error). Exercise: Individuals were regarded as regular physical exercisers if they performed moderate exercise at least 5 times per week for at least 30 min per session or performed vigorous exercise at least 3 times per week for at least 20 min per session. PTN, peridontal treatment needs; PT, permanent teeth.

Multivariate logistic regression analyses were applied to examine the odds ratios and $95 \% \mathrm{CI}$ of tooth brushing $\geq 3$ per day and the use of secondary oral products according to the SES. There are four logistic regression models. Model 1 was adjusted with age, gender and BMI. Adjustments were then made for the same variables as Model 1 plus smoking, drinking, and regular physical exercise (Model 2). Adjustments were made for the variables in Model 2 plus energy intake, fat intake, and periodontal treatment needs (CPI $\geq 3$ ) (Model 3). In addition, adjustments were made for the variables in Model 3 plus education or income (Model 4).

\section{Results}

Participant characteristics. Table I describes the characteristics of the study population, whom were grouped according to the daily frequency of tooth brushing and the use of secondary oral products. Tooth brushing frequency and the use of secondary products differed significantly depending on various factors. Individuals who brushed $\geq 3$ times per day were younger with lower BMI, lower waist circumference and less periodontal treatment needs. In current smokers, $35.8 \%$ brushed less than twice, $30.4 \%$ brushed twice and $24.2 \%$ 


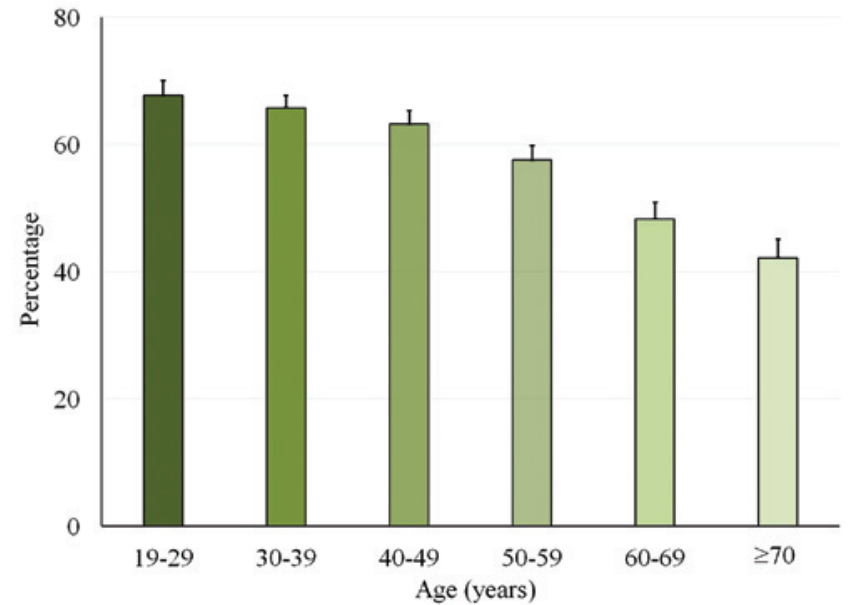

Figure 1. Percentage of participants who reported a daily tooth brushing frequency of $\geq 3$, grouped according to age.

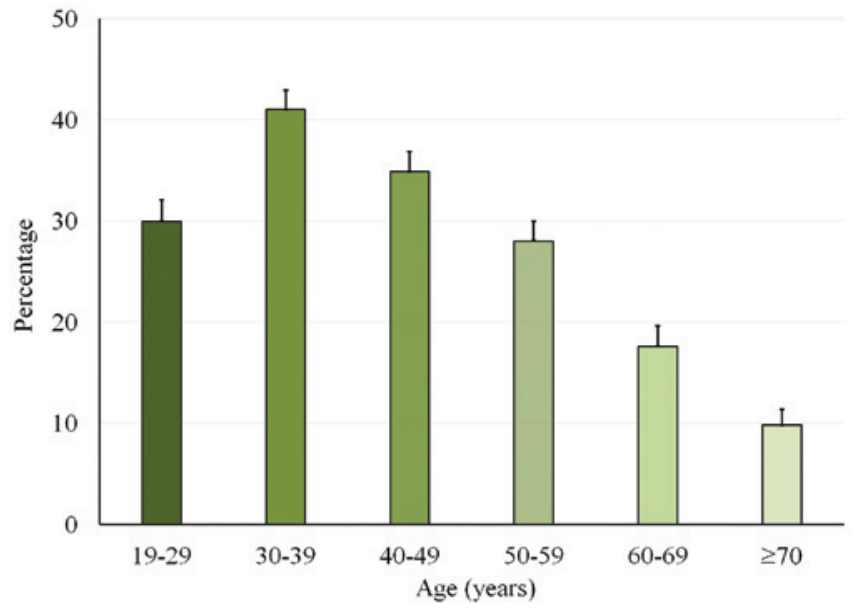

Figure 2. Percentage of participants who reported using secondary oral products, grouped according to age.

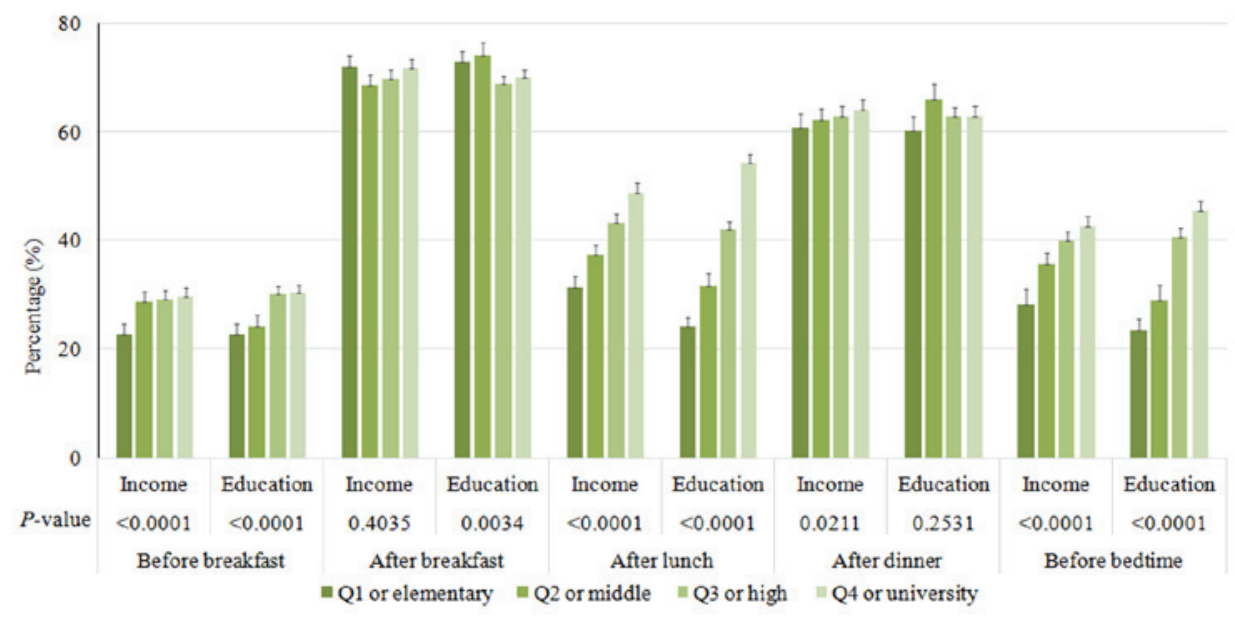

Figure 3. Tooth brushing characteristics of the study population, grouped according to socioeconomic status. "Statistically significant differences were detected among the groups.

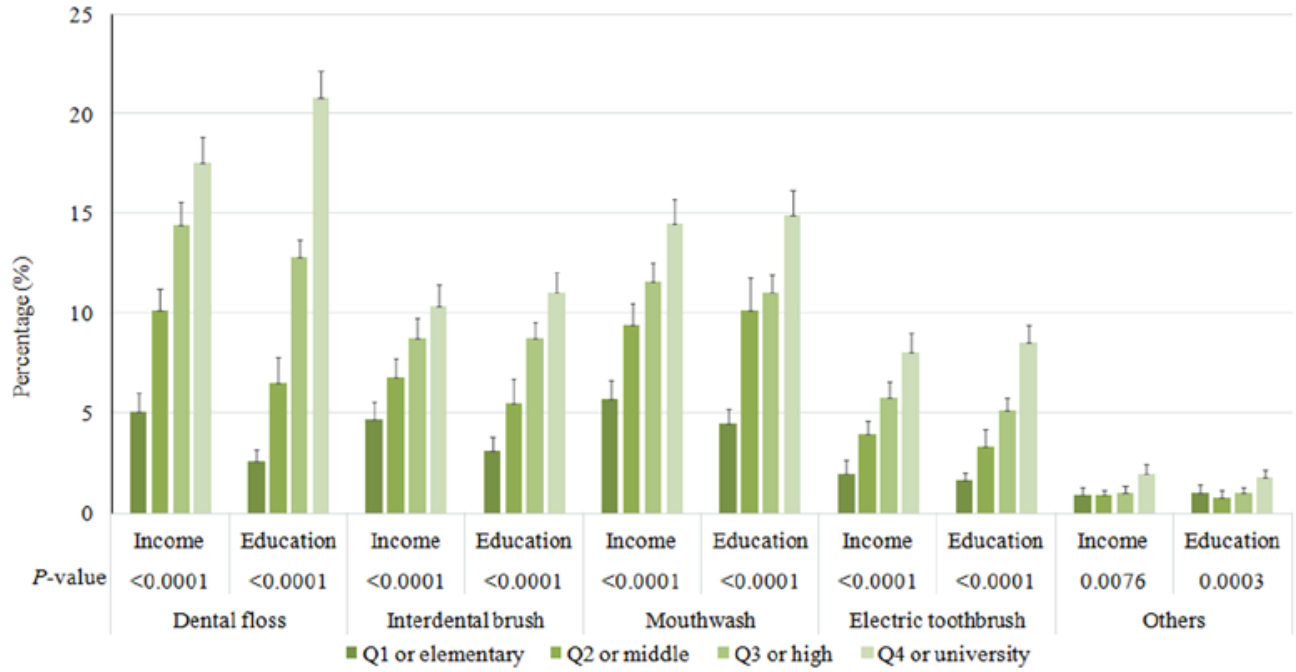

Figure 4. Characteristics of the study population regarding the use of secondary oral products, grouped according to the socioeconomic status. "Statistically significant differences were detected among the groups. 
Table II. Association between socioeconomic status and tooth brushing frequency and the use of secondary oral products.

\begin{tabular}{|c|c|c|c|c|c|c|c|c|}
\hline \multirow[b]{2}{*}{ Variable } & \multicolumn{3}{|c|}{ Daily tooth brushing frequency } & \multirow[b]{2}{*}{ P-value } & \multicolumn{3}{|c|}{ Daily use of secondary oral products } & \multirow[b]{2}{*}{ P-value } \\
\hline & $0-1$ & 2 & $\geq 3$ & & 0 & 1 & $\geq 2$ & \\
\hline Income & & & & $<.0001$ & & & & $<.0001$ \\
\hline Q1 & $26.4(1.5)$ & $18.2(0.7)$ & $12.9(0.6)$ & & $18.8(0.6)$ & $9.5(0.6)$ & $4.4(0.7)$ & \\
\hline $\mathrm{Q} 2$ & $29.4(1.5)$ & $26.7(0.9)$ & $24.3(0.7)$ & & $27.3(0.7)$ & $22.2(0.9)$ & $18.5(1.5)$ & \\
\hline Q3 & $25.1(1.4)$ & $28.6(0.9)$ & $30.2(0.7)$ & & $28.3(0.7)$ & $31.8(0.9)$ & $31.3(1.5)$ & \\
\hline Q4 & $19.1(1.5)$ & $26.5(1.1)$ & $32.6(0.9)$ & & $25.7(0.8)$ & $36.4(1.3)$ & $45.9(1.8)$ & \\
\hline Education & & & & $<.0001$ & & & & $<.0001$ \\
\hline Elementary school & $33.6(1.6)$ & $24.2(0.9)$ & $13(0.5)$ & & $23.2(0.7)$ & $7.6(0.5)$ & $3.5(0.6)$ & \\
\hline Middle school & $12.6(0.9)$ & $12(0.5)$ & $9(0.3)$ & & $11.4(0.3)$ & $8.4(0.5)$ & $4.8(0.7)$ & \\
\hline High school & $34.6(1.7)$ & $40(0.9)$ & $40.9(0.7)$ & & $39.6(0.7)$ & $42.6(0.9)$ & $37(1.8)$ & \\
\hline University & $19.3(1.3)$ & $23.8(0.9)$ & $37.1(0.8)$ & & $25.9(0.7)$ & $41.3(1.1)$ & $54.7(1.9)$ & \\
\hline
\end{tabular}

Data are represented as percentages (standard error). Q1, first quartile; Q2, second quartile; Q3, third quartile; Q4, fourth quartile.

brushed $\geq 3$ times per day. Similar trends were detected in the use of secondary oral products (Table I). It should be noted that the characteristics of the study population differed between the groups categorized by the number of times tooth brushing was carried out and the use of secondary oral products .

Age. Participants who brushed $\geq 3$ times per day according to age are presented in Fig. 1. The incidence of individuals who brushed $\geq 3$ times per day decreased with increasing age. The use of secondary oral products according to age is presented in Fig. 2. Participants aged between 30 and 39 years exhibited the highest percentage of secondary oral product usage. The results suggest that age was associated with oral health behaviors.

Socioeconomic factors. It was demonstrated that the time of day that tooth brushing occurred differed according to socioeconomic factors (Fig. 3). At the majority of the time points, participants in the highest quartile of income were most likely to brush their teeth. Similarly, individuals with the highest education were more likely to brush their teeth at the most of the time points. Socioeconomic factors were also associated with the use of secondary oral products (Fig. 4). Participants in the highest quartile of income and highest education were more likely to use dental floss, interdental brushes, mouthwash and electric toothbrushes. Participants who brushed $\geq 3$ times per day exhibited the highest proportion of individuals in the highest quartile of income, and individuals who used more than one type of secondary oral product had a higher proportion in the highest quartile of income and education level, as compared with the other groups (Table II). Furthermore, participants in the highest quartile of income were most likely to have had a dental examination within the past year, as compared with the other quartiles (Table III). Similarly, individuals who had completed a higher level of education (high school graduate or higher) were more likely to have had a dental examination within the past year, as compared with the lower levels of education, which were defined as less than a high school degree. The results suggested that socioeconomic factors are associated with oral health behaviors.
Table III. Association between socioeconomic status and attendance at a dental checkup within a year.

\begin{tabular}{|c|c|c|c|}
\hline & \multicolumn{2}{|c|}{$\begin{array}{l}\text { Dental checkup } \\
\text { within a year }\end{array}$} & \multirow[b]{2}{*}{ P-value } \\
\hline & No & Yes & \\
\hline Income & & & $<.0001$ \\
\hline Q1 & $17.6(0.6)$ & $10.2(0.7)$ & \\
\hline Q2 & $26.8(0.7)$ & $21.5(0.9)$ & \\
\hline Q3 & $29.3(0.7)$ & $29.4(1.0)$ & \\
\hline Q4 & $26.3(0.8)$ & $38.9(1.4)$ & \\
\hline Education & & & $<.0001$ \\
\hline Elementary school & $20.6(0.6)$ & $11.6(0.6)$ & \\
\hline Middle school & $10.7(0.3)$ & $8.8(0.5)$ & \\
\hline High school & $40.3(0.7)$ & $39.3(0.9)$ & \\
\hline University & $28.4(0.7)$ & $40.2(1.1)$ & \\
\hline
\end{tabular}

Data are presented as percentages (standard error). Q1, first quartile; Q2, second quartile; Q3, third quartile; Q4, fourth quartile.

Tables IV and V present the adjusted odds ratios and 95\% CIs from multiple logistic regression analyses. The association detected between the frequency of tooth brushing and SES remained after all adjustment models (Table IV). Adjusted odds ratios and their 95\% CIs were 1.086 (0.941-1.253), 1.158 (1.006-1.334), and 1.264 (1.094-1.460) for the second, third and fourth quartiles of income, respectively (Model 4). Adjusted odds ratios and their $95 \%$ CIs for the middle school, high school, and university or higher graduate groups were 1.475 (1.268-1.716), 1.765 (1.537-2.026), and 2.686 (2.286-3.155), respectively (Model 4). The association between the use of secondary oral products and SES remained after adjustment (Table V). Adjusted odds ratios and their 95\% CIs were 1.266 (1.092-1.469), 1.599 (1.371-1.865), and 1.835 (1.559-2.161) for 
Table IV. Multivariate logistic regression model analysis of socioeconomic status for participants who reported $\geq 3$ tooth brushing incidences per day.

\begin{tabular}{lcccc}
\hline Variables & Model 1 & Model 2 & Model 3 & Model 4 \\
\hline Income & & & & 1 \\
Q1 & 1 & 1 & $1.174(1.017-1.354)$ & $1.086(0.941-1.253)$ \\
Q2 & $1.188(1.04-1.356)$ & $1.178(1.032-1.345)$ & $1.351(1.173-1.555)$ & $1.158(1.006-1.334)$ \\
Q3 & $1.384(1.212-1.580)$ & $1.358(1.190-1.548)$ & $1.606(1.387-1.859)$ & $1.264(1.094-1.460)$ \\
Q4 & $1.686(1.468-1.936)$ & $1.635(1.424-1.877)$ & $<.0001$ & 0.0007 \\
P-value for trend & $<.0001$ & $<.0001$ & 1 & 1 \\
Education & & & $1.530(1.318-1.776)$ & $1.475(1.268-1.716)$ \\
Elementary school & $1.543(1.344-1.772)$ & $1.498(1.304-1.722)$ & $1.862(1.618-2.142)$ & $1.765(1.537-2.026)$ \\
Middle school & $2.002(1.744-2.297)$ & $1.931(1.684-2.215))$ & $2.920(2.468-3.455)$ & $2.686(2.286-3.155)$ \\
High school & $3.158(2.701-3.692)$ & $2.998(2.563-3.508)$ & $<.0001$ & $<.0001$ \\
University & $<.0001$ & $<.0001$ & & \\
P-value for trend & & & & \\
\hline
\end{tabular}

Data are presented as the adjusted odds ratio (95\% confidence interval). Model 1, age, gender, and body mass index adjusted; Model 2, model $1+$ smoking, drinking and exercise adjusted; Model 3, model 2 + energy intake, fat intake and periodontitis (CPI $\geq 3$ ) adjusted; Model 4, model 3 + education or income adjusted.

Table V. Multivariate logistic regression model analysis of participants who reported using secondary oral products.

\begin{tabular}{|c|c|c|c|c|}
\hline Variables & Model 1 & Model 2 & Model 3 & Model 4 \\
\hline \multicolumn{5}{|l|}{ Income } \\
\hline Q1 & 1 & 1 & 1 & 1 \\
\hline Q2 & $1.548(1.346-1.78)$ & $1.523(1.324-1.751)$ & $1.505(1.295,1.75)$ & $1.266(1.092,1.469)$ \\
\hline Q3 & $2.160(1.868-2.498)$ & $2.121(1.834-2.453)$ & $2.116(1.815,2.468)$ & $1.599(1.371,1.865)$ \\
\hline Q4 & $2.899(2.498-3.365)$ & $2.825(2.435-3.277)$ & $2.730(2.321,3.212)$ & $1.835(1.559,2.161)$ \\
\hline P for trend & $<.0001$ & $<.0001$ & $<.0001$ & $<.0001$ \\
\hline \multicolumn{5}{|l|}{ Education } \\
\hline Elementary school & 1 & 1 & 1 & 1 \\
\hline Middle school & $2.647(2.218-3.159)$ & $2.543(2.128-3.038)$ & $2.483(2.057-2.997)$ & $2.231(1.849-2.692)$ \\
\hline High school & $4.448(3.782-5.232)$ & $4.314(3.671-5.069)$ & $4.279(3.595-5.094)$ & $3.669(3.085-4.364)$ \\
\hline University & $7.487(6.284-8.920)$ & $7.344(6.164-8.748)$ & $7.196(5.948-8.705)$ & $5.736(4.734-6.951)$ \\
\hline $\mathrm{P}$ for trend & $<.0001$ & $<.0001$ & $<.0001$ & $<.0001$ \\
\hline
\end{tabular}

Data are presented as the adjusted odds ratio (95\% confidence interval). Model 1, age, gender, and body mass index adjusted; Model 2, model $1+$ smoking, drinking and exercise adjusted; Model 3, model $2+$ energy intake, fat intake and periodontal treatment needs (CPI $\geq 3$ ) adjusted; Model 4, model 3 + education or income adjusted.

the second, third and fourth quartiles of income, respectively (Model 4). Adjusted odds ratios and their 95\% CIs for the middle school, high school, and university or higher graduate groups were 2.231 (1.849-2.692), 3.669 (3.085-4.364), and 5.736 (4.734-6.951), respectively (Model 4). The results demonstrate an association between SES and oral health behaviors in a large sample of the Korean population.

\section{Discussion}

The present study assessed the association between SES and oral health behaviors in a large sample of the Korean population.
The results demonstrated that the oral health behavior of the individuals investigated differed significantly depending on their demographic characteristics. Tooth brushing frequency differed significantly depending on age, gender, BMI, waist circumference, energy intake, and fat intake. The type of residential area (urban/rural), incidence of dental checkups within a year, smoking and drinking also affected the frequency of tooth brushing, confirming the results of a previous study (24).

Reports of tooth brushing frequency vary among different studies (25-27). A previous study performed in the United Kingdom,withasamplesize of 13,400 households,demonstrated that $75 \%$ of the population performed twice-daily brushing. 
However, in another previous report, 761 adolescents were randomly selected from both public and private schools in Goiania, which is a large town in middle-west Brazil (27), and the daily tooth brushing frequency was reported as once to twice among $22.3 \%$ of respondents and $\geq 3$ times among $77.7 \%$. Therefore, this study showed that the majority of the adolescent participants brushed their teeth three times per day. A previous study has suggested that the high levels of plaque and calculus in individuals who brush twice daily, suggesting that there is still room for improving the efficacy of brushing (25).

A previous study has demonstrated that individuals who cleaned their teeth at least twice a day exhibited less visible plaque, as compared with those who cleaned their teeth less than once a day or never (25). Similarly, this study showed that the percentage of participants who required periodontal treatment decreased as the frequency of tooth brushing increased, confirming the results of a previous study (24). Regular attendance at a routine oral health examination has been encouraged for the maintenance of oral health and this practice has acquired an increased importance with the publication of the evidence-based guideline on dental recall (25). It was demonstrated that dentate adults who reported regular dental checkups were less likely to have visible plaque $(61 \%)$ than individuals who reported only attending the dentist when it was necessary (76\%) (25). This study suggested that participants who brushed more were more likely to have had a dental examination within the past year.

Previous studies have demonstrated an association between SES and oral health behavior (27-29). Lower income and fewer years of education are reported to increase the risk for oral disease (29). A previous study identified the socioeconomic factors associated with the prevalence of periodontal treatment needs, and it was demonstrated that participants with a higher income were less likely to require periodontal treatment (11). Income may be a barrier to the use of dental services and the availability of dental insurance, and individuals with lower incomes may be less aware of the need for proper dental care $(30,31)$. Individuals with low education levels, defined as less than a high school degree, had a higher prevalence of tooth loss in a previous study (29). Similarly, in young children, the prevalence of tooth brushing was higher among the children of mothers with higher education, as compared with those born to mothers with a lower education (32). Furthermore, it has been demonstrated that the type of school (middle or high) and school grade may affect the oral health behavior of adolescents (24). Therefore, individuals who have completed a lower level of education may lack oral health knowledge. A previous report demonstrated that the odds ratio of the lowest income category,as compared with the highest, was 3.74 on the decayed missing filled teeth index (33). For participants with the lowest income and education, this study showed that the odds ratios of tooth brushing frequency were 1.264 and 2.686 , respectively. Similarly, the odds ratios of the lowest income and education for the use of secondary oral products were 1.835 and 5.736, respectively. Access for dental care may be limited due to lack of funds, which may perpetuate a lack of oral health care knowledge and lead to a higher prevalence of individuals with periodontal treatment needs. This suggests that it is necessary for individuals in lower income/education quartiles to be targeted for public health education.
The present study demonstrated an association between SES and oral health behaviors in a large sample of the Korean population. Within the limits of the present study, income and education were suggested as potential risk indicators for oral health behaviors; therefore, patients with a low SES should be investigated further, in relation to oral health.

\section{Acknowledgements}

The present research was supported by the Basic Science Research Program through the National Research Foundation of Korea funded by the Ministry of Science, ICT \& Future Planning (grant no. NRF-2014R1A1A1003106). The authors thank the Korea Centers for Disease Control and Prevention for providing data.

\section{References}

1. Jin LJ, Lamster IB, Greenspan JS, Pitts NB, Scully C and Warnakulasuriya S: Global burden of oral diseases: Emerging concepts, management and interplay with systemic health. Oral Dis, 2015.

2. Linden GJ, Lyons A and Scannapieco FA: Periodontal systemic associations: Review of the evidence. J Clin Periodontol 40 Suppl 14: S8-19, 2013.

3. Singh A, Rouxel P, Watt RG and Tsakos G: Social inequalities in clustering of oral health related behaviors in a national sample of British adults. Prev Med 57: 102-106, 2013.

4. Espinoza I, Thomson WM, Gamonal J and Arteaga O: Disparities in aspects of oral-health-related quality of life among Chilean adults. Community Dent Oral Epidemiol 41: 242-250, 2013.

5. Astrom AN, Haugejorden O, Skaret E, Trovik TA and Klock KS: Oral Impacts on daily performance in norwegian adults: The influence of age, number of missing teeth, and socio-demographic factors. Eur J Oral Sci 114: 115-121, 2006.

6. Thomson WM: Social inequality in oral health. Community Dent Oral Epidemiol 40 (Suppl 2): S28-S32, 2012.

7. Paula JS, Ambrosano GM and Mialhe FL: The impact of social determinants on schoolchildren's oral health in Brazil. Braz Oral Res 29: 1-9, 2015.

8. Wennstrom A, Ahlqwist M, Stenman U, Bjorkelund C and Hakeberg M: Trends in tooth loss in relation to socio-economic status among Swedish women, aged 38 and 50 years: Repeated cross-sectional surveys 1968-2004. BMC Oral Health 13: 63, 2013.

9. Paganini-Hill A, White SC and Atchison KA: Dental health behaviors, dentition, and mortality in the elderly: the leisure world cohort study. J Aging Res 2011: 156061, 2011.

10. Hayasaka K, Tomata Y, Aida J, Watanabe T, Kakizaki M and Tsuji I: Tooth loss and mortality in elderly Japanese adults: Effect of oral care. J Am Geriatr Soc 61: 815-820, 2013.

11. Kim DW, Park JC, Rim TT, Jung UW, Kim CS, Donos N, Cha IH and Choi SH: Socioeconomic disparities of periodontitis in Koreans based on the KNHANES IV. Oral Dis 20: 551-559, 2014.

12. Kim YH, Cho KH, Choi YS, Kim SM, Nam GE, Lee SH, Ko BJ, Park YG, Han KD, Lee KS and Kim DH: Low bone mineral density is associated with metabolic syndrome in South Korean men but not in women: The 2008-2010 Korean national health and nutrition examination survey. Arch Osteoporos 8: $142,2013$.

13. Korea Center for Disease Control and Prevention: Korea National Health and Nutrition Examination Survey. 2008. Available at: http://knhanes.cdc.go.kr.

14. Nam GE, Cho KH, Park YG, Han KD, Choi YS, Kim SM, Lee KS, Ko BJ, Kim YH, Han BD and Kim do H: Socioeconomic status and dyslipidemia in Korean adults: The 2008-2010 Korea national health and nutrition examination survey. Prev Med 57: 304-309, 2013.

15. Kim YH, Kim DH, Lim KS, Ko BJ, Han BD, Nam GE, Park YG, Han KD, Kim JH and Cho KH: Oral health behaviors and metabolic syndrome: The 2008-2010 Korean national health and nutrition examination survey. Clin Oral Investig 18: 1517-1524, 2014. 
16. Oh JY, Yang YJ, Kim BS and Kang JH: Validity and reliability of Korean version of International Physical Activity Questionnaire (IPAQ) short form. Journal of the Korean Academy of Family Medicine 28: 532-541, 2007.

17. Lee K: Body composition and vitamin D status: The Korea national health and nutrition examination survey IV (KNHANES IV). J Hum Nutr Diet 26 (Suppl 1): S105-S113, 2013.

18. Kim DW, Song S, Lee JE, Oh K, Shim J, Kweon S, Paik HY and Joung H: Reproducibility and validity of an FFQ developed for the Korea National Health and Nutrition Examination Survey (KNHANES). Public Health Nutr 18: 1369-1377, 2015.

19. Nam GE, Kim do H, Cho KH, Park YG, Han KD, Choi YS, Kim SM, Ko BJ, Kim YH and Lee KS: Estimate of a predictive cut-off value for serum 25-hydroxyvitamin D reflecting abdominal obesity in Korean adolescents. Nutr Res 32: 395-402, 2012.

20. Susin C, Kingman A and Albandar JM: Effect of partial recording protocols on estimates of prevalence of periodontal disease. J Periodontol 76: 262-267, 2005.

21. Kingman A, Susin C and Albandar JM: Effect of partial recording protocols on severity estimates of periodontal disease. J Clin Periodontol 35: 659-667, 2008.

22. Kim EJ, Jin BH and Bae KH: Periodontitis and obesity: A study of the fourth Korean national health and nutrition examination survey. J Periodontol 82: 533-542, 2011.

23. Lee JB, Yi HY and Bae KH: The association between periodontitis and dyslipidemia based on the fourth Korea national health and nutrition examination survey. J Clin Periodontol 40: 437-442, 2013

24. Kim HY, Kim Y, Hwang JM and Park YD: Oral health behaviours according to demographic characteristics in Korean adolescents: A national representative sample. Int Dent J 61: 168-173, 2011.
25. Hill KB, Chadwick B, Freeman R, O'Sullivan I and Murray JJ: Adult dental health survey 2009: Relationships between dental attendance patterns, oral health behaviour and the current barriers to dental care. Br Dent J 214: 25-32, 2013

26. Gibson S and Williams S: Dental caries in pre-school children: Associations with social class, toothbrushing habit and consumption of sugars and sugar-containing foods. Further analysis of data from the national diet and nutrition survey of children aged 1.5-4.5 years. Caries Res 33: 101-113, 1999.

27. Freire MC, Sheiham A and Hardy R: Adolescents' sense of coherence, oral health status, and oral health-related behaviours. Community Dent Oral Epidemiol 29: 204-212, 2001.

28. Armfield JM, Mejia GC and Jamieson LM: Socioeconomic and psychosocial correlates of oral health. Int Dent J 63: 202-209, 2013.

29. Jiang Y, Okoro CA, Oh J and Fuller DL: Sociodemographic and health-related risk factors associated with tooth loss among adults in Rhode Island. Prev Chronic Dis 10: E45, 2013.

30. Bayat F, Vehkalahti MM, Zafarmand AH and Tala H: Impact of insurance scheme on adults' dental check-ups in a developing oral health care system. Eur J Dent 2: 3-10, 2008.

31. Kiyak HA and Reichmuth M: Barriers to and enablers of older adults' use of dental services. J Dent Educ 69: 975-986, 2005.

32. Casanova-Rosado AJ, Medina-Solis CE, Casanova-Rosado JF, Vallejos-Sánchez AA, Maupomé G and Avila-Burgos L: Dental caries and associated factors in Mexican schoolchildren aged 6-13 years. Acta Odontol Scand 63: 245-251, 2005.

33. Geyer S, Schneller T and Micheelis W: Social gradients and cumulative effects of income and education on dental health in the fourth german oral health study. Community Dent Oral Epidemiol 38: 120-128, 2010. 